\title{
Developing Canadian Defined Daily Doses for Animals: A Metric to Quantify Antimicrobial Use
}

\author{
Angelina L. Bosman ${ }^{1,2 *}$, Daleen Loest ${ }^{1}$, Carolee A. Carson ${ }^{1}$, Agnes Agunos ${ }^{1}$, \\ Lucie Collineau $^{3}$ and David F. Léger ${ }^{1}$ \\ ${ }^{1}$ Centre for Food-borne, Environmental and Zoonotic Infectious Diseases, Public Health Agency of Canada, Guelph, ON, \\ Canada, ${ }^{2}$ Population Medicine, Ontario Veterinary College, University of Guelph, Guelph, ON, Canada, ${ }^{3}$ Public Health Risk \\ Sciences Division, National Microbiology Laboratory, Public Health Agency of Canada, Guelph, ON, Canada
}

\section{OPEN ACCESS}

Edited by:

loannis Magouras,

City University of Hong Kong,

Hong Kong

Reviewed by:

Cedric Muentener,

University of Zurich, Switzerland

Merel Postma

Ghent University, Belgium

${ }^{*}$ Correspondence:

Angelina L. Bosman

bosmana@uoguelph.ca

Specialty section: This article was submitted to Veterinary Epidemiology and Economics,

a section of the journal

Frontiers in Veterinary Science

Received: 30 March 2019 Accepted: 18 June 2019

Published: 17 July 2019

Citation:

Bosman AL, Loest D, Carson CA, Agunos $A$, Collineau $L$ and Léger DF (2019) Developing Canadian Defined Daily Doses for Animals: A Metric to Quantify Antimicrobial Use.

Front. Vet. Sci. 6:220

doi: 10.3389/fvets.2019.00220
Antimicrobial use surveillance data need to be analyzed and reported in a standardized and harmonized way. In veterinary medicine, one approach is to use defined daily doses (DDD) for animals. DDD for animals are technical standards used in various measures or metrics that quantify antimicrobial use. The European Medicines Agency published principles for assigning DDDvet values based on information on dosing obtained from nine European countries. For measuring antimicrobial use in livestock within Canada, DDDs for animals reflective of Canadian veterinary antimicrobial use (DDDvetCAs) were needed. Our objectives were (1) to describe the development of DDDvetCA standards for pigs and poultry (broiler chickens and turkeys) for authorized and compounded antimicrobial active ingredients used in Canada, including those used extra-label; and (2) to compare the DDDvetCAs with EMA's DDDvets, where possible. Species-specific DDDvetCAs were assigned based on the average of unique antimicrobial daily doses obtained from product information, stratified by route of administration and age indication (where applicable). The feed, water and bolus DDDvetCAs were compared to oral DDDvets, and injectable DDDvetCAs to parenteral DDDvets, that matched by antimicrobial active ingredient. Seventy-five DDDvetCAs were assigned for pigs; 51 for poultry. Seventeen injectable DDDvetCAs could be compared to 14 EMA's parenteral DDDvets and 53 feed, water, and bolus DDDvetCAs could be compared to 40 oral DDDvets. Feed and water DDDvetCAs were generally lower than EMA's oral DDDvets, although differences in methodology between Canada and Europe make comparisons challenging. The assignment of DDDvetCAs was a resource intensive and iterative process. EMA's published principles for assigning DDDvets were an invaluable source of information. The use of DDDvetCAs will reflect exposure of Canadian animals to antimicrobials, be useful for evaluating associations between use and resistance within Canada and provide information for risk assessment and stewardship policies. However, when reporting antimicrobial use data internationally, using the same DDD standards as other reporting countries will facilitate between country comparisons, although differences in which antimicrobial active ingredients are licensed between countries may create challenges. Future steps include assigning DDDvetCAs for other food animal species, such as cattle, veal, and farmed fish.

Keywords: DDDvet, antimicrobial usage, veterinary, Canada, surveillance 


\section{INTRODUCTION}

Antimicrobials have an important role in food animal production. Their use to treat, control, and prevent infections plays a part in the sustainability of food animal production (1). However, antimicrobial use (AMU), in both humans and animals, has led to the emergence of antimicrobial resistance (AMR), with a subsequent increased incidence of infections that are more difficult to treat (2). These infections have significant impacts on humans, with an estimated 700,000 people globally dying every year of drug-resistant infections in the world (2), and likely a significant impact on animals, though this information is not often reported.

For these reasons, some countries conduct surveillance of antimicrobials used in animals (3-5). The Public Health Agency of Canada's Canadian Integrated Program for Antimicrobial Resistance Surveillance (CIPARS) conducts AMU surveillance in food animals (5). These surveillance activities align with various national and international initiatives and action plans to address the threat of AMR (6-8). CIPARS currently reports information provided by the Canadian Animal Health Institute on the quantities of antimicrobial agents distributed for use in animals. For 2018 data, CIPARS will be reporting on antimicrobials sold for use in animals. This data, collected under new legislative authority, will be provided by pharmaceutical manufacturers, importers, and compounders. At the farm level, CIPARS currently collects information on AMU and AMR in grower-finisher pigs, broiler chickens, and turkeys, with the aim to expand surveillance into other food animal sectors (5). This information is used to fulfill the objectives of the CIPARS farm surveillance component which are to monitor trends in antimicrobial use in select species of livestock (5).

Data gathered by AMU surveillance programs must be analyzed and reported in a standardized and harmonized way to draw conclusions that are as accurate as possible. In addition to monitoring trends in AMU, these data are needed to develop effective farm and veterinary interventions, inform antimicrobial stewardship, and to provide information for risk assessment.

One approach for animal AMU analysis and reporting is to apply a defined daily dose (DDD) for animals. The DDD for animals is a technical unit of measurement developed by the European Medicines Agency's (EMA) European Surveillance of Veterinary Antimicrobial Consumption (ESVAC) project (9). ESVAC coined the term DDDvet to describe their DDD for animals, which are used in various metrics to quantify AMU (9). The DDD are used to adjust the kilograms of active antimicrobial ingredients (AAIs) by the daily dose of the antimicrobial, measured in mg per kilogram of animal (9). This concept is based on the globally accepted DDD in human medicine (10).

\footnotetext{
Abbreviations: AMU, antimicrobial use; AMR, antimicrobial resistance; AAI, active antimicrobial ingredient; CIPARS, Canadian Integrated Program for Antimicrobial Resistance Surveillance; DDD, defined daily dose; DDD for animals, defined daily doses for animals; DDDvetCA, Canadian defined daily doses for animals; DDDvet, European Medicines Agency defined daily doses for animals; EMA, European Medicines Agency; ESVAC, European Surveillance of Veterinary Antimicrobial Consumption.
}

The creation (or assignment) of standardized DDD for animals involves determining an average dose for each AAI authorized for use in the species of interest by route of administration (9). The principles of DDD assignment may also be extended to AAIs authorized for use in another species and used in an extra-label manner in the species of interest. As technical standards, these assigned DDDs are not meant to be considered recommended doses and may not represent doses that are used in practice (9). Instead, the assigned DDDs simply provide standard doses that can be used to facilitate standardized measurements of AMU. These standardized measurements can be used to examine trends in AMU over time, to compare of AMU between different regions, across species, and different AAIs, and to examine associations between AMU and AMR (9).

Accounting for dose when analyzing and reporting AMU is important since dosing between antimicrobials varies. This variation in dose may be due to differences in mechanism of action, pharmaceutical formulations, and metabolism and distribution in the body (11). To demonstrate the importance of accounting for dose when comparing antimicrobial use on two farms, we have provided the following hypothetical example. During one production cycle, farm A gives a single injection of ceftiofur to 100 grower-finisher pigs at $3 \mathrm{mg} / \mathrm{kg}$, and farm B gives a single injection of tiamulin to 100 grower-finisher pigs at $11 \mathrm{mg} / \mathrm{kg}$. Both farms have 1,000 grower-finisher pigs (with an average weight at treatment of $65 \mathrm{~kg}$ ). Farm A used 19,500 mg of ceftiofur, which equals $0.3 \mathrm{mg}$ per $\mathrm{kg}$ of animal, while farm $B$ used $71,500 \mathrm{mg}$ of tiamulin, equal to $1.1 \mathrm{mg} / \mathrm{kg}$ of animal. From a weight perspective, farm $\mathrm{A}$ appears to have used less antimicrobial than farm $B$, yet each farmer administered the same number of treatments to the same number of animals. If we adjust the kilograms of antimicrobial used by the dose, we find that both farm A and B used 6,500 DDD for animals (kg). Another way to interpret this value is say that both farms treated $6,500 \mathrm{~kg}$ of pig with one daily dose of antimicrobial. By adjusting the weight of the antimicrobial given by its DDD for animals, comparisons in use between antimicrobials with different doses are more informative.

In 2015, the EMA published principles for assigning DDDvets (9) with the goal to harmonize where possible with the methodology published by the World Health Organization (10). EMA's published principles for assigning DDDvets were invaluable in informing and guiding this project (9). These principles for assigning DDDvets were followed in 2016 by the publication of EMA assigned DDDvets for pigs, cattle and poultry, based on product information on dosing for veterinary antimicrobials obtained from Summaries of Product Characteristics (SPC) from nine European countries (12). Prior to the publication of DDDvets by the EMA, Postma et al. (13) had described assigning defined daily dose animal (DDDA) for each antimicrobial product authorized for use in pigs, using product information from four European countries. Other countries have developed national DDD for animals, including the Netherlands and Denmark, although different terminology is used to describe them $(14,15)$.

Using the principles for assigning DDDvets published by EMA, CIPARS decided to develop Canadian DDD for animals 
(DDDvetCAs). The decision to develop DDDvetCAs was made because of expected differences in antimicrobials between Canada and other countries, including antimicrobials registered for use, antimicrobial doses, the number of unique doses for an antimicrobial, and indications for use. Standardized DDD for animals based on antimicrobials authorized for use in Canada were needed for the analysis of AMU within a Canadian context. The primary objective of this study was to develop DDDvetCAs for all antimicrobials authorized (or otherwise known to be used in an extra-label manner) for use in Canada, starting with pigs and poultry (including broiler chickens and turkeys). A secondary objective was to compare DDDvetCAs with EMA's DDDvets for both species.

\section{METHODS}

We used the EMA's Principles for the assignment of defined daily doses for animals as guidance in the assignment of DDDvetCAs for pigs and poultry, with minor changes as required (9).

\section{Collection of Antimicrobial Daily Dose Information}

Decisions about which antimicrobials and which doses to include in the assignment of DDDvetCAs differed in some ways to decisions made by EMA. In contrast to EMA, we assigned DDDvetCAs to coccidiostats and ionophores, as farm surveillance data about their use are collected and they are classified in Canada as antimicrobials. Also included were antimicrobials with growth promotion properties, such as bacitracin, virginiamycin, and avilamycin. Compounded antimicrobials with no equivalent authorized product in the species of interest and those used in an extra-label manner were also included, with evidence of use from Canadian surveillance data. Extra-label drug use was defined as use of an antimicrobial in a species or by route of administration not described on the label.

Daily doses from antimicrobial products authorized for use in Canada were obtained from product information found in the Canadian Compendium of Veterinary Products (16) and the Compendium of Medicating Ingredient Brochures (17). Information on doses for compounded antimicrobials were obtained from a survey in one province, that collected the prescribed dose from the label applied to the product by the veterinarian (Cécile Ferrouillet, personal communication, 2017). Doses for antimicrobials used in an extra-label manner were obtained from expert opinion (Agnes Agunos, personal communication, 2016; Anne Deckert, personal communication, 2016).

Microsoft Excel $^{\circledR}$ (2010) was used to tabulate the unique daily doses for each AAI, regardless of indication. Doses were stratified by species and route of administration (in feed, in water, by injection, and by individual oral treatment or bolus). While EMA chose to group oral routes of administration together, we chose to keep them in separate categories. Since product information for feed and water medications often include doses in units such as $\mathrm{mg} / \mathrm{kg}$ feed or $\mathrm{mg} / \mathrm{L}$ water, conversion to $\mathrm{mg} / \mathrm{kg}$ body weight was required. To do so, these doses were multiplied by either the feed or water to weight conversion ratio (in $\mathrm{kg}$ feed per $\mathrm{kg}$ animal or in $\mathrm{L}$ water per $\mathrm{kg}$ animal), as per ESVAC (9). Also, in most cases, only treatment and prevention doses were tabulated; growth promotion doses were excluded, except where the only doses available for an antimicrobial were for growth promotion purposes. This exception applied to most coccidiostats and ionophores in pigs, and to bambermycin and benzylpenicillin used in feed in poultry. These doses were clearly labeled as growth promotion doses in order to clearly identify where they were used.

Due to heterogeneity in drug product information, decisions had to be made during the tabulation of product doses (Figure 1). If the product information recommended an initial loading dose followed by a maintenance dose, the daily dose was determined by calculating the total dose given over the recommended number of days of treatment, divided by the recommended number of days. For combination products containing more than one AAI, the daily dose of each AAI in the combination was determined by multiplying the dose of the combination product by the proportion of each AAI in the product. If a dose range was reported, the mean of the range was used to assign the DDDvetCA. If the dose was expressed in international units, the dose was converted to mg with conversion factors used by the EMA (18). To obtain a daily dose for longacting injectable products, the dose was divided by either the duration of action (in days) if available, or the recommended dosing frequency (e.g., every 3 days) if the duration of action was not available. In some instances, we contacted product manufacturers to get information about durations of action when the product information was unclear (i.e., tulathromycin, and benzathine benzylpenicillin, and procaine benzylpenicillin). When the concentration of an AAI was reported as both a salt and a base, the salt concentration was used to calculate the daily dose. For example, an in-feed product containing tiamulin for use in pigs indicated that $1 \mathrm{~kg}$ of product contained $100 \mathrm{~g}$ of tiamulin hydrogen fumarate (the salt), equaling $80.9 \mathrm{~g}$ of tiamulin base. In this case, the salt concentration of $100 \mathrm{~g} / \mathrm{kg}$ was used to calculate the daily dose.

The distribution of doses was examined by calculating the minimum, maximum, and median daily doses for each AAI, in addition to the mean daily dose. To compare the mean daily dose (DDDvetCA) to the median dose, a ratio was calculated using Equation (1).

$$
\text { Ratio mean }: \text { median dose }=\text { DDDvetCA } / \text { median dose }
$$

\section{Additional Information Recorded}

In addition to dose information, the Health Canada Category of the AAI was recorded (19). These categories include Category IVery high importance (to human medicine), Category II-High importance, Category III-Medium importance and Category IV-Low importance (19). These categories are distinguished by their importance in human medicine and the availability of effective alternatives should resistance occur. Health Canada category I and II antimicrobials are used to treat serious infections in humans, however, if resistance to category II 


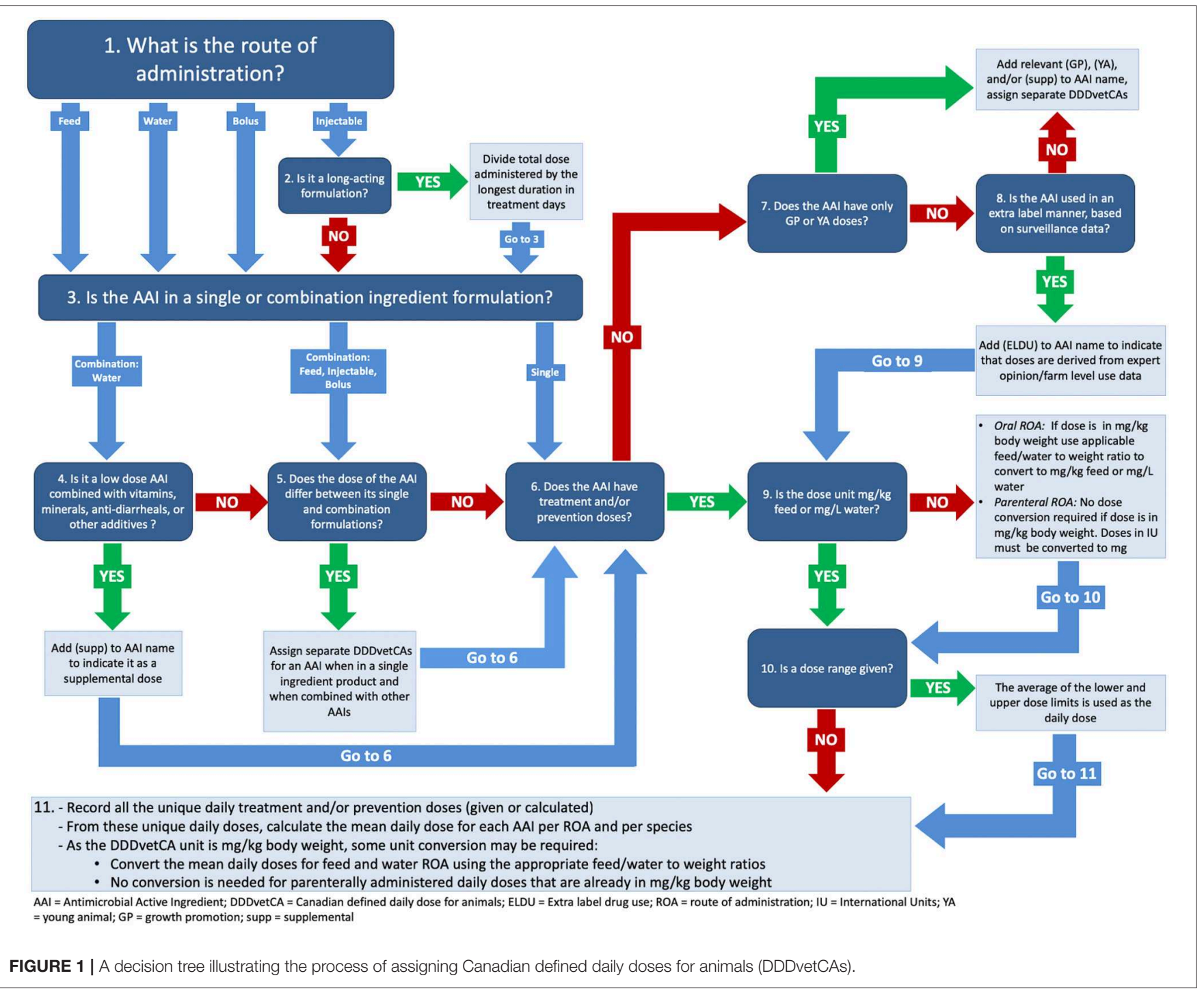

TABLE 1 | Example calculation of the mean daily dose and the Canadian defined daily dose for animals (DDDvetCA) for selected antimicrobial active ingredients and routes of administration, in poultry and pigs.

\begin{tabular}{|c|c|c|c|c|c|c|c|}
\hline Species & $\begin{array}{l}\text { Antimicrobial } \\
\text { active ingredient }\end{array}$ & $\mathrm{ROA}^{\mathrm{a}}$ & $\begin{array}{l}\text { Number of products } \\
\text { marketed in Canada }\end{array}$ & Unique dosages & Mean daily dose & $\begin{array}{l}\text { Feed or water } \\
\text { WCR }^{\mathrm{c}, \mathrm{d}}\end{array}$ & $\begin{array}{c}\text { DDDvetCA (mg/kg } \\
\text { BW/day) }\end{array}$ \\
\hline \multirow[t]{2}{*}{ Pigs } & Chlortetracycline & Feed & 12 & $55,110,220,656$ & $260.3 \mathrm{mg} / \mathrm{kg}$ feed & 0.04 & 10.4 \\
\hline & Tylosin & Water & 2 & 83,250 & 166.5 mg/L water & 0.1 & 16.7 \\
\hline Poultry & Bacitracin & Feed & 3 & $55,82.5,110$ & $77.9 \mathrm{mg} / \mathrm{kg}$ feed & 0.13 & 10.1 \\
\hline
\end{tabular}

${ }^{a}$ Route of administration.

${ }^{b}$ Canadian Animal Health Institute (16).

${ }^{c} W C R$, weight conversion ratio in $\mathrm{kg}$ feed $/ \mathrm{kg}$ animal or $\mathrm{L}$ water $/ \mathrm{kg}$ animal.

${ }^{d}$ European Medicines Agency (9).

${ }^{e} B W$, body weight.

${ }^{f}$ Not applicable.

antimicrobials occurs, category I antimicrobials could be substituted; there are no substitutes for antimicrobials in category I (19). Category III antimicrobials are less essential due to the availability of alternatives in categories I and II (19). Category IV antimicrobials include flavophospholipols and ionophores, which are not currently used in human medicine (19). 


\section{Assignment of DDDvetCAs}

The DDDvetCAs, in $\mathrm{mg} / \mathrm{kg}$ animal body weight per day, were assigned by calculating the mean of the tabulated unique daily doses for each AAI, stratified by species and route of administration. Examples of mean daily dose calculations can be found in Table 1. The mean daily dose was assigned as the DDDvetCA for that antimicrobial and route of administration. Generally, an AAI was assigned one DDDvet per route of administration, except for some AAIs used in combination. Following ESVAC's guidelines, when the dose of an AAI differed between single and combination ingredient use, due to a synergistic effect, the AAI was assigned two separate DDDvetCAs (9). One DDDvetCA was assigned based on the daily dose for single ingredient use and a second DDDvetCA was assigned based on the daily dose for combination ingredient use. For example, in poultry, the single ingredient formulation dose for lincomycin in water was $16 \mathrm{mg} / \mathrm{L}$, while the lincomycin-spectinomycin formulation dose for lincomycin in water was $277.5 \mathrm{mg} / \mathrm{L}$ (16). In this case, two DDDvets were calculated, one for single use lincomycin, and one for lincomycin when administered as a combination product containing both lincomycin and spectinomycin. We followed ESVAC's convention of identifying DDDvets for antimicrobials used in combination as: antimicrobial 1_antimicrobial 2, which is understood as the DDDvetCA for antimicrobial 1 when it is used in combination with antimicrobial 2. In a similar situation, long-acting injectable ceftiofur in pigs was assigned a separate DDDvetCA from conventional injectable ceftiofur as the daily dose between the two formulations differed ( 1 and 3 $\mathrm{mg} / \mathrm{kg}$, respectively). Finally, consistent with EMA guidelines (9), we assigned prodrugs their own DDDvetCAs (e.g., procaine benzylpenicillin).

Specific decisions were required for doses for animals in specific age categories. Most antimicrobial products approved for use in feed and water did not differentiate doses by the age or production stage of the animal. However, some injectable and oral bolus product information included doses specific to young animals. For example, injectable gentamicin had doses for young pigs and chicks only (16). In addition, AMU data collected in Canada may be stratified by production stage in some species (e.g., farrowing, nursery or grow-finish stage in pigs). For this reason, we used these young animal doses to assign separate DDDvetCA specific to young animals, where applicable, which is a difference between our approach and that of EMA (9).

These young animal doses were often reported as a "per animal" dose. To obtain a dose in $\mathrm{mg} / \mathrm{kg}$ these doses were divided by the average weight of the animal at treatment (16). For chicks and turkey poults, this weight was obtained from expert opinion (0.042 and $0.06 \mathrm{~kg}$, respectively) (Agnes Agunos, personal communication, 2016). For piglets, we used ESVAC's standard piglet weight ( $4 \mathrm{~kg}$ ) (9), which we confirmed to be consistent with Canadian pig production by expert opinion (Anne Deckert, personal communication, 2016). These young animal DDDvetCAs were labeled as such, to identify them as separate from the regular DDDvetCAs.
Another decision was required for handling products containing a mixture of various ingredients, such as antidiarrheals, vitamins, minerals, and other additives, combined with very low doses of antimicrobials (16). The degree to which these products are used in pig production is not known, and with upcoming regulatory changes to require prescriptions for all medically important antimicrobials, these products may change or cease to be available (20). For these reasons, we assigned separate DDDvetCAs for the AAIs in these products. As with the young animal DDDvetCAs, the DDDvetCAs assigned using these low, or supplemental, doses were clearly labeled as such.

\section{Comparison Between DDDvetCAs and EMA's DDDvets}

Decisions made by EMA and CIPARS differed in how the DDDs for animals were stratified by route of administration, making comparisons between the two sets of DDDs challenging (9). While acknowledging that the differences in stratification by route of administration could contribute to differences between the DDDvetCAs and the DDDvets, we compared feed, water and bolus DDDvetCAs to oral DDDvets that matched by AAI. We also compared injectable DDDvetCAs with parenteral DDDvets that matched by AAI.

Comparisons between DDDvetCAs and DDDvets were made by calculating the ratio of the DDDvetCA to the DDDvet using Equation (2) for each matching DDDvet by species and route of administration. Ratios of one $( \pm 10 \%)$ were considered equal. Ratios above 1.1 indicated the DDDvetCA was larger than DDDvet, while ratios below 0.9 indicated the DDDvetCA was smaller. Ratios above 1.5 and below 0.5 , indicating a more than $50 \%$ disparity between the two values, were considered to indicate a substantial difference between the two standards.

$$
\text { Ratio DDDvetCA }: \text { DDvet }=\text { DDDvetCA } / D D D v e t
$$

\section{RESULTS}

\section{Poultry}

An examination of the distribution of daily AAI doses showed that, for poultry, doses often varied widely for a given AAI (Table 2). An example of the variation in doses was sulfamethazine for administration through water, with a daily dose range of $143.8-335.4 \mathrm{mg} / \mathrm{kg}$ (Table 2). Sixty-seven percent of the DDDvetCAs included products with a single dose for all indications. Seventy-eight percent of the median and mean daily doses were equal; notable exceptions included amprolium in feed ( mean dose $=20.7$, median $=16.3, \mathrm{mg} / \mathrm{kg}$ /day) (Table 2). When the mean and median dose differed, the median dose was smaller than the mean dose.

\section{Antimicrobial Products and AAls}

The distribution of antimicrobial products by route of administration is illustrated in Figure 2. We did not identify any antimicrobial products for use by individual oral treatment (bolus), as poultry are generally not given individual oral treatments. Most products and AAI were for use in-feed (Figures 2, 3). Six in feed AAIs were ionophores and eight were 
TABLE 2 | The minimum, maximum, and median doses for all antimicrobial active ingredients for which Canadian defined daily doses for animals (DDDvetCAs) were assigned for poultry, by route of administration, and the number of products used to assign each DDDvetCA.

\begin{tabular}{|c|c|c|c|c|c|c|}
\hline $\begin{array}{l}\text { Route of } \\
\text { admin }\end{array}$ & Antimicrobial active ingredient ${ }^{a, b}$ & $\begin{array}{l}\text { Minimum } \\
\text { dose }\end{array}$ & $\begin{array}{c}\text { Maximum } \\
\text { dose }\end{array}$ & $\begin{array}{l}\text { Median } \\
\text { dose }\end{array}$ & $\begin{array}{l}\text { Ratio mean: } \\
\text { median dose }\end{array}$ & $\begin{array}{c}\text { Number of } \\
\text { products }\end{array}$ \\
\hline Feed & Amprolium & 13.3 & 32.5 & 16.3 & 1.27 & 1 \\
\hline Feed & Avilamycin & 2.9 & 2.9 & 2.9 & 1.00 & 1 \\
\hline Feed & Bacitracin & 7.2 & 13.1 & 10.1 & 1.00 & 3 \\
\hline Feed & Bambermycin (GP) & 0.3 & 0.3 & 0.3 & 1.15 & 1 \\
\hline Feed & Chlortetracycline & 7.2 & 28.6 & 14.3 & 1.17 & 3 \\
\hline Feed & Clopidol & 16.3 & 16.3 & 16.3 & 1.00 & 1 \\
\hline Feed & Decoquinate & 3.9 & 3.9 & 3.9 & 1.00 & 1 \\
\hline Feed & Diclazuril & 0.1 & 0.1 & 0.1 & 1.00 & 1 \\
\hline Feed & Erythromycin & 28.6 & 28.6 & 28.6 & 1.00 & 1 \\
\hline Feed & Halofuginone & 0.4 & 0.4 & 0.4 & 1.00 & 1 \\
\hline Feed & Lasalocid & 13.0 & 13.7 & 13.3 & 1.00 & 2 \\
\hline Feed & Maduramicin ammonium & 0.7 & 0.7 & 0.7 & 1.00 & 1 \\
\hline Feed & Monensin & 13.0 & 13.0 & 13.0 & 1.00 & 3 \\
\hline Feed & Narasin & 9.1 & 9.1 & 9.1 & 1.00 & 2 \\
\hline Feed & Narasin_nicarbazin & 5.2 & 5.2 & 5.2 & 1.00 & 1 \\
\hline Feed & Nicarbazin & 10.4 & 26.0 & 16.3 & 1.06 & 1 \\
\hline Feed & Nicarbazin_narasin & 5.2 & 5.2 & 5.2 & 1.00 & 1 \\
\hline Feed & Oxytetracycline & 7.2 & 28.6 & 14.3 & 1.17 & 8 \\
\hline Feed & Benzylpenicillin (GP) & 0.3 & 0.3 & 0.3 & 1.05 & 2 \\
\hline Feed & Procaine benzylpenicillin & 5.4 & 5.4 & 5.4 & 1.00 & 2 \\
\hline Feed & Robenidine & 4.3 & 4.3 & 4.3 & 1.00 & 1 \\
\hline Feed & Salinomycin & 7.8 & 7.8 & 7.8 & 1.00 & 5 \\
\hline Feed & Semduramicin & 3.3 & 3.3 & 3.3 & 1.00 & 1 \\
\hline Feed & Sulfadiazine_trimethoprim (ELDU) & 10.8 & 10.8 & 10.8 & 1.00 & 1 \\
\hline Feed & Trimethoprim_sulfonamide (ELDU) & 2.2 & 2.2 & 2.2 & 1.00 & 1 \\
\hline Feed & Tylosin & 26.0 & 26.0 & 26.0 & 1.00 & 4 \\
\hline Feed & Virginiamycin & 2.9 & 2.9 & 2.9 & 1.00 & 4 \\
\hline Feed & Zoalene (Dinitolmide) & 16.3 & 24.3 & 20.3 & 1.00 & 1 \\
\hline Water & Amoxicillin & 12.0 & 12.0 & 12.0 & 1.00 & 2 \\
\hline Water & Amprolium & 55.2 & 55.2 & 55.2 & 1.00 & 1 \\
\hline Water & Apramycin (ELDU) & 23.0 & 23.0 & 23.0 & 1.00 & 1 \\
\hline Water & Enrofloxacin (ELDU) & 5.8 & 5.8 & 5.8 & 1.00 & 1 \\
\hline Water & Erythromycin & 13.3 & 26.6 & 19.9 & 1.00 & 1 \\
\hline Water & Lincomycin & 3.7 & 3.7 & 3.7 & 1.00 & 2 \\
\hline Water & Lincomycin_spectinomycin & 63.8 & 63.8 & 63.8 & 1.00 & 2 \\
\hline Water & Neomycin & 8.1 & 55.8 & 20.4 & 1.07 & 8 \\
\hline Water & Oxytetracycline & 5.6 & 40.9 & 18.6 & 1.01 & 11 \\
\hline Water & Benzylpenicillin & 41.0 & 41.0 & 41.0 & 1.00 & 4 \\
\hline Water & Benzylpenicillin (supp) & 3.8 & 3.8 & 3.8 & 1.00 & 3 \\
\hline Water & Pyrimethamine_sulfaquinoxaline & 3.4 & 3.4 & 3.4 & 1.00 & 1 \\
\hline Water & Spectinomycin_lincomycin & 127.7 & 127.7 & 127.7 & 1.00 & 2 \\
\hline Water & Streptomycin (supp) & 19.6 & 19.6 & 19.6 & 1.00 & 3 \\
\hline Water & Sulfamethazine & 143.8 & 335.4 & 230.0 & 1.03 & 4 \\
\hline Water & Sulfaquinoxaline & 58.4 & 87.5 & 72.9 & 1.00 & 2 \\
\hline Water & Sulfaquinoxaline_pyrimethamine & 11.2 & 11.2 & 11.2 & 1.00 & 1 \\
\hline Water & Tetracycline & 11.1 & 40.9 & 20.4 & 1.05 & 13 \\
\hline Water & Tylosin & 28.8 & 115.0 & 71.9 & 1.00 & 2 \\
\hline Injectable & Ceftiofur (ELDU) (YA) & 2.6 & 2.6 & 2.6 & 1.00 & 1 \\
\hline
\end{tabular}


TABLE 2 | Continued

\begin{tabular}{|c|c|c|c|c|c|c|}
\hline $\begin{array}{l}\text { Route of } \\
\text { admin }\end{array}$ & Antimicrobial active ingredient ${ }^{a, b}$ & $\begin{array}{l}\text { Minimum } \\
\text { dose }\end{array}$ & $\begin{array}{l}\text { Maximum } \\
\text { dose }\end{array}$ & $\begin{array}{l}\text { Median } \\
\text { dose }\end{array}$ & $\begin{array}{l}\text { Ratio mean: } \\
\text { median dose }\end{array}$ & $\begin{array}{c}\text { Number of } \\
\text { products }\end{array}$ \\
\hline Injectable & Gentamicin (YA) & 4.8 & 16.8 & 10.8 & 1.00 & 1 \\
\hline Injectable & Lincomycin_spectinomycin (ELDU) (YA) & 6.0 & 6.0 & 6.0 & 1.00 & 1 \\
\hline Injectable & Spectinomycin_lincomycin (ELDU) (YA) & 12.0 & 12.0 & 12.0 & 1.00 & 1 \\
\hline
\end{tabular}

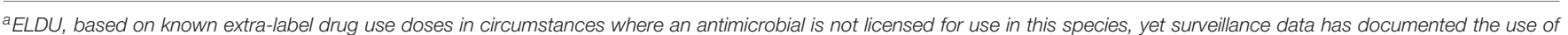

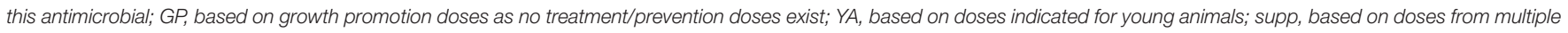
ingredient products with low doses of antimicrobials.

${ }^{b}$ Antimicrobial active ingredients written as: Active ingredient 1_active ingredient $2=D D D v e t C A$ for active ingredient 1 when used in combination with active ingredient 2.

${ }^{c}$ Ratio mean:median dose $=$ DDDvetCA/median dose.

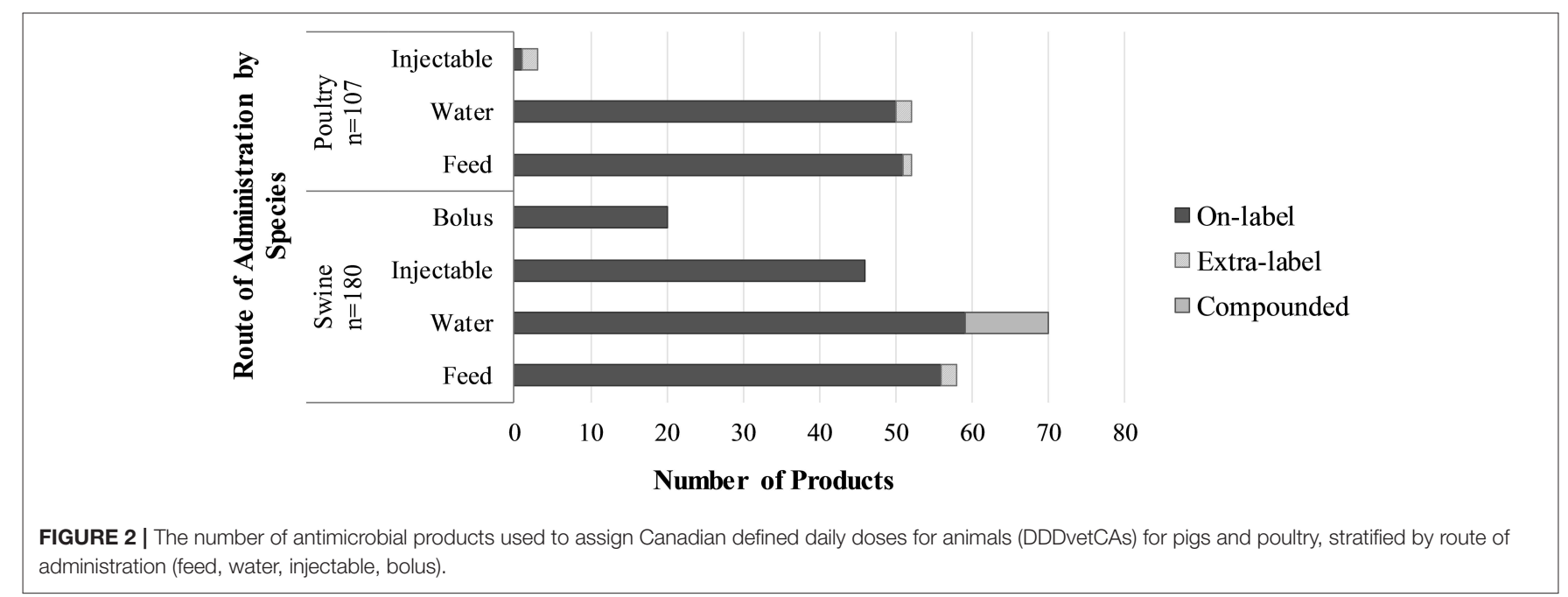

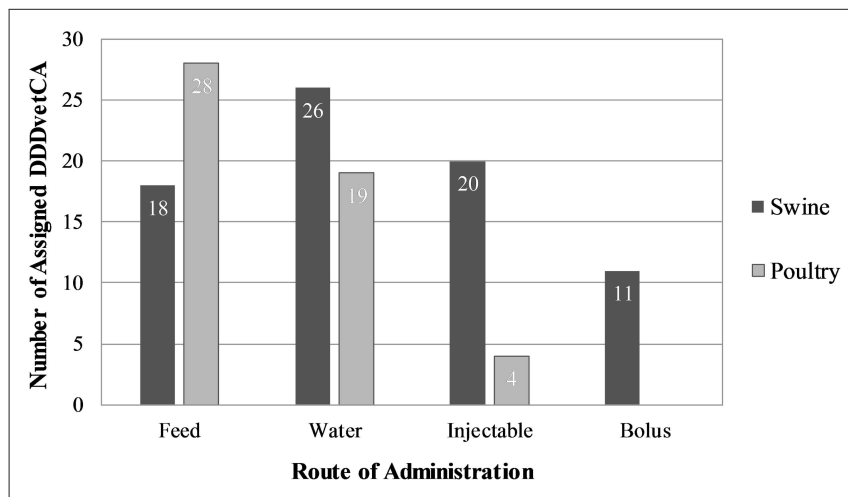

FIGURE 3 | The number of assigned Canadian defined daily doses for animals (DDDvetCAs) by species and route of administration, including coccidiostats and ionophores.

synthetic coccidiostats. The AAI with the most products was oxytetracycline (19 products).

\section{DDDvetCAs}

The complete list of DDDvetCAs assigned for poultry can be found in Table 3. Feed was the route of administration with the most assigned DDDvetCAs (Figure 3). Two of the in feed DDDvetCAs (bambermycin and benzylpenicillin) were based only on growth promotion doses (Table 3). All four of the injectable DDDvetCAs were assigned for young chicks/poults only (Table 3). Three of these young animal injectable DDDvetCAs (ceftiofur, lincomycin-spectinomycin, spectinomycin-lincomycin) were based on extra-label drug use (ELDU) doses as the injectable products containing these AAIs do not include doses for poultry in the product information, however, surveillance data indicate use in the hatcheries. Other DDDvetCAs assigned from extra-label use doses included enrofloxacin and apramycin in water, and trimethoprimsulfadiazine in feed (Table 3). The DDDvetCA for injectable gentamicin was assigned based on subcutaneous doses for chicks and poults from the product information, although gentamicin may be used off-label in-ovo. No DDDvetCAs were assigned for poultry based on compounded product doses at this time (Table 3).

\section{Comparison Between DDDvetCAs and EMA's DDDvets}

In poultry, comparisons between DDDvetCAs and DDDvets were only possible for the feed and water routes of administration, as the European Union/European Economic Area countries do not have any parenteral antimicrobials products approved for poultry. Nineteen DDDvetCAs 
TABLE 3 | The Canadian defined daily doses for animals (DDDvetCA) in $\mathrm{mg} / \mathrm{kg}_{\text {poultry }} /$ day for antimicrobials used in poultry production, by antimicrobial active ingredient and route of administration.

\begin{tabular}{|c|c|}
\hline Antimicrobial active ingredient ${ }^{a, b}$ & DDDvetCA (mg/kg/day) \\
\hline \multicolumn{2}{|l|}{ FEED } \\
\hline Amprolium & 20.7 \\
\hline Avilamycin & 2.9 \\
\hline Bacitracin & 10.1 \\
\hline Bambermycin (GP) & 0.3 \\
\hline Chlortetracycline & 16.7 \\
\hline Clopidol & 16.3 \\
\hline Decoquinate & 3.9 \\
\hline Diclazuril & 0.1 \\
\hline Erythromycin & 28.6 \\
\hline Halofuginone & 0.4 \\
\hline Lasalocid & 13.3 \\
\hline Maduramicin ammonium & 0.7 \\
\hline Monensin & 13 \\
\hline Narasin & 9.1 \\
\hline Narasin_nicarbazin & 5.2 \\
\hline Nicarbazin & 17.2 \\
\hline Nicarbazin_narasin & 5.2 \\
\hline Oxytetracycline & 16.7 \\
\hline Penicillin G (GP) & 0.3 \\
\hline Procaine penicillin G & 5.4 \\
\hline Robenidine & 4.3 \\
\hline Salinomycin & 7.8 \\
\hline Semduramicin & 3.3 \\
\hline Sulfadiazine_trimethoprim (ELDU) & 10.8 \\
\hline Trimethoprim_sulfadiazine (ELDU) & 2.2 \\
\hline Tylosin & 26 \\
\hline Virginiamycin & 2.9 \\
\hline Zoalene (Dinitolmide) & 20.3 \\
\hline \multicolumn{2}{|l|}{ WATER } \\
\hline Amoxicillin & 12 \\
\hline Amprolium & 55.2 \\
\hline Apramycin (ELDU) & 23 \\
\hline Enrofloxacin (ELDU) & 5.8 \\
\hline Erythromycin & 19.9 \\
\hline Lincomycin & 3.7 \\
\hline Lincomycin_spectinomycin & 63.8 \\
\hline Neomycin & 27.3 \\
\hline Oxytetracycline & 18.8 \\
\hline Penicillin G & 41 \\
\hline Penicillin G (supp) & 3.8 \\
\hline Pyrimethamine_sulfaquinoxaline & 3.4 \\
\hline Spectinomycin_lincomycin & 127.7 \\
\hline Streptomycin (supp) & 19.6 \\
\hline Sulfamethazine & 236.4 \\
\hline Sulfaquinoxaline & 72.9 \\
\hline Sulfaquinoxaline_pyrimethamine & 11.2 \\
\hline Tetracycline & 21.4 \\
\hline Tylosin & 71.9 \\
\hline
\end{tabular}

(Continued)
TABLE 3 | Continued

Antimicrobial active ingredient ${ }^{a, b}$

DDDvetCA (mg/kg/day)

\begin{tabular}{lc}
\hline INJECTABLE & \\
Ceftiofur (ELDU) (YA) & 2.6 \\
Gentamicin (YA) & 10.8 \\
Lincomycin_spectinomycin (ELDU) (YA) & 6 \\
Spectinomycin_lincomycin (ELDU) (YA) & 12 \\
\hline
\end{tabular}

a DDDvetCA, Canadian defined daily dose for animals; LA, long-acting; YA, young animal doses; supp, supplements; ELDU, extra-label drug use; GP, growth promotion dose.

${ }^{b}$ Antimicrobial active ingredients written as: Active ingredient 1_active ingredient 2 = DDDvetCA for active ingredient 1 when used in combination with active ingredient 2.

could be compared to DDDvets (Table 4). For 34 feed and water DDDvetCAs there were no corresponding DDDvets for comparison.

Results of the comparison showed some similarities and differences between the two sets of DDD for animals. Table 5 shows the frequency and proportion of DDDvetCA that were larger, smaller, or equivalent to their corresponding DDDvet according to the DDDvetCA/DDDvet ratio. More specifically, the DDDvetCAs and the DDDvets for erythromycin, neomycin and tylosin in water were similar with ratios between 0.9 and 1.1 . Overall for poultry, five (26\%) of the DDDvetCAs were larger and $11(58 \%)$ of the DDDvetCAs were smaller than the corresponding DDDvets. DDDvetCAs that were notably different from the DDDvet included lincomycin combined with spectinomycin. Overall, nine DDDvetCAs (47\%) differed by more than $50 \%$ from the equivalent DDDvets, with ratios $<0.5$ or $>1.5$.

\section{Other Observations}

An examination of the Health Canada categorization of all DDDvetCAs in poultry revealed two Health Canada Category I AAIs, namely ceftiofur and enrofloxacin, which are used extra-label in poultry. Thirteen AAIs were Category II, with the remainder in Categories III and IV, or uncategorized (19). Uncategorized AAIs included avilamycin (an orthosomycin antimicrobial), tiamulin (a pleuromutilin antimicrobial), pyrimethamine (an anti-protozoal usually combined with sulfaquinoxaline), and the chemical coccidiostats.

\section{Pigs}

As observed for poultry, an examination of the distribution of daily AAI doses showed that, for pigs, doses often varied widely for a given AAI. Like poultry, an example of a wide difference between the minimum and maximum daily dose of an AAI in pig was sulfamethazine in water, with minimum and maximum daily doses of 7 and $135 \mathrm{mg} / \mathrm{kg}$, respectively (Table 6). Oxytetracycline, chlortetracycline, and bacitracin in feed had mean daily doses that varied from the median by a ratio of $>1.5$ (Table 5). Eightyone percent of the median daily doses were identical to the median. Like poultry, the median dose was smaller than the mean dose in pigs, except for tiamulin in feed and neomycin (supplemental) bolus (Table 6). 
TABLE 4 | The ratio of the Canadian defined daily doses for animals (DDDvetCA) by water, feed and oral bolus routes of administration to the European Medicine Agency's defined daily dose for animals (DDDvet) by the oral route of administration in poultry.

\begin{tabular}{|c|c|c|c|c|c|}
\hline Antimicrobial active ingredient ${ }^{a, b}$ & DDDvetCA & Canadian ROA & DDDvet $^{c}$ & EMA ROA ${ }^{\mathrm{d}}$ & Ratio $^{\mathrm{e}}$ \\
\hline Amoxicillin & 12 & Water & 16 & Oral & 0.8 \\
\hline Apramycin & 23 & Water & 81 & Oral & 0.3 \\
\hline Chlortetracycline & 16.7 & Feed & 30 & Oral & 0.6 \\
\hline Enrofloxacin & 5.8 & Water & 10 & Oral & 0.6 \\
\hline Erythromycin & 28.6 & Feed & 20 & Oral & 1.4 \\
\hline Erythromycin & 19.9 & Water & 20 & Oral & 1.0 \\
\hline Lincomycin & 3.7 & Water & 8.6 & Oral & 0.4 \\
\hline Lincomycin_spectinomycin & 63.8 & Water & 22 & Oral & 2.9 \\
\hline Neomycin & 27.3 & Water & 24 & Oral & 1.1 \\
\hline Oxytetracycline & 16.7 & Feed & 39 & Oral & 0.4 \\
\hline Oxytetracycline & 18.8 & Water & 39 & Oral & 0.5 \\
\hline Spectinomycin_lincomycin & 127.7 & Water & 38 & Oral & 3.4 \\
\hline Sulfadiazine_trimethoprim & 10.8 & Feed & 34 & Oral & 0.3 \\
\hline Sulfamethazine & 236.4 & Water & 182 & Oral & 1.3 \\
\hline Sulfaquinoxaline & 72.9 & Water & 60 & Oral & 1.2 \\
\hline Tetracycline & 21.4 & Water & 71 & Oral & 0.3 \\
\hline Trimethoprim_sulfadiazine & 2.2 & Feed & 6.4 & Oral & 0.3 \\
\hline Tylosin & 26 & Feed & 81 & Oral & 0.3 \\
\hline Tylosin & 71.9 & Water & 81 & Oral & 0.9 \\
\hline
\end{tabular}

Ratios above 1.5 and below 0.5, indicating substantial differences in these standardized doses, are in bold print.

${ }^{a}$ Antimicrobial active ingredients written as: Active ingredient 1_active ingredient $2=$ DDDvetCA for active ingredient 1 when used in combination with active ingredient 2.

${ }^{b}$ ELDU, extra-label drug use.

${ }^{c}$ European Medicines Agency (12).

${ }^{d}$ The EMA combined in feed, in water and oral bolus routes of administration into one oral DDDvet.

${ }^{e}$ Ratio, DDDvetCAVDDDvet.

TABLE 5 | The frequency and proportion of Canadian defined daily doses for animals (DDDvetCA) that were larger, smaller, or equivalent to their corresponding defined daily dose for animals (DDDvet ${ }^{\mathrm{a}}$ ), by species and route of administration.

\begin{tabular}{|c|c|c|c|c|}
\hline Species & Route of administration & $\begin{array}{c}\text { DDDvetCA:DDDvet } \\
\text { Ratio >1.1 N (\%) }\end{array}$ & $\begin{array}{c}\text { DDDvetCA:DDDvet } \\
\text { Ratio <0.9 N (\%) }\end{array}$ & $\begin{array}{l}\text { DDDvetCA:DDDvet Ratio } \\
\geq 0.9 \text { and } \leq 1.1 N(\%)\end{array}$ \\
\hline Poultry & Feed & $1(17)$ & $5(83)$ & $0(0)$ \\
\hline Poultry & Water & $4(31)$ & $6(46)$ & $3(23)$ \\
\hline Pigs & Feed & $0(0)$ & $11(100)$ & $0(0)$ \\
\hline Pigs & Water & $5(29)$ & $7(41)$ & $5(29)$ \\
\hline Pigs & Injectable & $5(29)$ & $6(35)$ & $6(35)$ \\
\hline Pigs & Bolus ${ }^{b}$ & $2(33)$ & $3(50)$ & $1(17)$ \\
\hline Poultry and pigs & All routes of administration & $17(24)$ & $38(54)$ & $15(21)$ \\
\hline
\end{tabular}

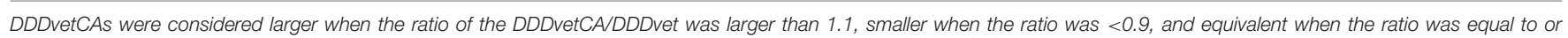
between 0.9 and 1.1 .

a European Medicines Agency (12).

${ }^{b}$ Bolus, administered as individual oral treatment.

\section{Antimicrobial Products and AAls}

The distribution of antimicrobial products by route of administration is illustrated in Figure 2. Most products (including ELDU and compounded products) and AAIs were for use in water (Figures 2, 3). Two in feed AAIs were ionophores and one was a synthetic coccidiostat. Like poultry, the AAI for which there were the most products was oxytetracycline (36 products).

\section{DDDvetCAs}

The complete list of assigned DDDvetCAs for pigs can be found in Table 7. The route of administration with the most assigned DDDvetCAs was in water (Figure 3). Two in water and three in feed DDDvetCAs were assigned based on growth promotion doses only, as these AAIs lacked doses for treatment or prevention (Table 7). Young animal DDDvetCAs were assigned for eleven bolus and four injectable AAIs (Table 7). 
TABLE 6 | The minimum, maximum, and median doses for all antimicrobial active ingredients for which Canadian defined daily doses for animals (DDDvetCAs) were assigned for pigs, by route of administration, and the number of products used to assign each DDDvetCA.

\begin{tabular}{|c|c|c|c|c|c|c|}
\hline $\begin{array}{l}\text { Route of } \\
\text { admin }^{a}\end{array}$ & Antimicrobial active ingredient ${ }^{b, c}$ & Minimum dose & Maximum dose & Median dose & $\begin{array}{l}\text { Ratio mean: } \\
\text { median dose }\end{array}$ & $\begin{array}{c}\text { Number of } \\
\text { products }\end{array}$ \\
\hline Feed & Avilamycin & 3.2 & 3.2 & 3.2 & 1.00 & 1 \\
\hline Feed & Bacitracin & 1.6 & 11.0 & 2.8 & 1.61 & 4 \\
\hline Feed & Bambermycin (ELDU) (GP) & 0.1 & 0.1 & 0.1 & 1.00 & 1 \\
\hline Feed & Chlortetracycline & 2.2 & 26.2 & 6.6 & 1.58 & 12 \\
\hline Feed & Lincomycin & 1.8 & 8.8 & 4.4 & 1.14 & 6 \\
\hline Feed & Lincomycin_spectinomycin & 0.9 & 0.9 & 0.9 & 1.00 & 2 \\
\hline Feed & Narasin (GP) & 0.6 & 0.6 & 0.6 & 1.00 & 2 \\
\hline Feed & Oxytetracycline & 2.0 & 22.0 & 4.4 & 1.73 & 13 \\
\hline Feed & Benzylpenicillin & 0.6 & 2.2 & 1.1 & 1.18 & 6 \\
\hline Feed & Procaine benzylpenicillin (ELDU) & 13.2 & 13.2 & 13.2 & 1.00 & 1 \\
\hline Feed & Salinomycin (GP) & 1.0 & 1.0 & 1.0 & 1.00 & 2 \\
\hline Feed & Spectinomycin_lincomycin & 0.9 & 0.9 & 0.9 & 1.00 & 2 \\
\hline Feed & Sulfamethazine & 4.4 & 4.4 & 4.4 & 1.00 & 5 \\
\hline Feed & Tiamulin & 1.5 & 8.8 & 6.3 & 0.90 & 4 \\
\hline Feed & Tilmicosin & 8.0 & 16.0 & 12.0 & 1.00 & 2 \\
\hline Feed & Tylosin & 1.8 & 4.4 & 3.1 & 1.00 & 7 \\
\hline Feed & Tylvalosin & 1.7 & 1.7 & 1.7 & 1.00 & 1 \\
\hline Feed & Virginiamycin & 2.2 & 4.4 & 3.3 & 1.00 & 4 \\
\hline Water & Amoxicillin & 16.0 & 16.0 & 16.0 & 1.00 & 2 \\
\hline Water & Ampicillin (C) & 20.0 & 20.0 & 20.0 & 1.00 & 1 \\
\hline Water & Apramycin & 10.0 & 10.0 & 10.0 & 1.00 & 1 \\
\hline Water & Gentamicin (C) & 1.1 & 1.1 & 1.1 & 1.00 & 1 \\
\hline Water & Lincomycin & 3.3 & 3.3 & 3.3 & 1.00 & 2 \\
\hline Water & Lincomycin_spectinomycin & 2.2 & 2.2 & 2.2 & 1.00 & 2 \\
\hline Water & Neomycin & 7.0 & 17.8 & 12.5 & 1.00 & 9 \\
\hline Water & Oxytetracycline & 5.0 & 33.3 & 13.6 & 1.07 & 11 \\
\hline Water & Benzylpenicillin & 17.8 & 17.8 & 17.8 & 1.00 & 3 \\
\hline Water & Benzylpenicillin (supp) (GP) & 3.6 & 3.6 & 3.6 & 1.00 & 3 \\
\hline Water & Phenoxymethylpenicillin (C) & 18.4 & 38.0 & 28.2 & 1.00 & 3 \\
\hline Water & Spectinomycin_lincomycin & 4.5 & 4.5 & 4.5 & 1.00 & 2 \\
\hline Water & Streptomycin (supp) (GP) & 18.4 & 18.6 & 18.5 & 1.00 & 3 \\
\hline Water & Sulfadiazine_trimethoprim (C) & 20.0 & 44.4 & 30.0 & 1.08 & 5 \\
\hline Water & Sulfamerazine (supp) & 2.5 & 4.1 & 3.3 & 1.00 & 4 \\
\hline Water & Sulfamethazine & 7.0 & 135.0 & 79.2 & 1.00 & 10 \\
\hline Water & Sulfamethazine (supp) & 6.3 & 6.3 & 6.3 & 1.00 & 3 \\
\hline Water & Sulfapyridine & 33.3 & 33.3 & 33.3 & 1.00 & 1 \\
\hline Water & Sulfathiazole & 37.8 & 75.0 & 39.3 & 1.18 & 6 \\
\hline Water & Sulfathiazole (supp) & 5.0 & 15.6 & 10.3 & 1.00 & 4 \\
\hline Water & Tetracycline & 2.0 & 17.8 & 8.3 & 1.04 & 12 \\
\hline Water & Tiamulin & 4.9 & 4.9 & 4.9 & 1.00 & 2 \\
\hline Water & Tilmicosin (C) & 10.0 & 10.0 & 10.0 & 1.00 & 1 \\
\hline Water & Trimethoprim_sulfadiazine (C) & 5.5 & 8.9 & 7.0 & 1.01 & 5 \\
\hline Water & Tylosin & 8.3 & 25.0 & 16.7 & 1.00 & 2 \\
\hline Water & Tylvalosin & 5.0 & 5.0 & 5.0 & 1.00 & 1 \\
\hline Injectable & Ampicillin & 6.0 & 6.0 & 6.0 & 1.00 & 1 \\
\hline Injectable & Benzathine benzylpenicillin combi (LA) & 1.2 & 1.2 & 1.2 & 1.00 & 1 \\
\hline Injectable & Ceftiofur & 3.0 & 3.0 & 3.0 & 1.00 & 6 \\
\hline Injectable & Ceftiofur (LA) & 1.0 & 1.0 & 1.0 & 1.00 & 1 \\
\hline Injectable & Enrofloxacin & 7.5 & 7.5 & 7.5 & 1.00 & 1 \\
\hline
\end{tabular}


TABLE 6 | Continued

\begin{tabular}{|c|c|c|c|c|c|c|}
\hline $\begin{array}{l}\text { Route of } \\
\text { admin }^{a}\end{array}$ & Antimicrobial active ingredient ${ }^{b, c}$ & Minimum dose & Maximum dose & Median dose & $\begin{array}{l}\text { Ratio mean: } \\
\text { median dose }\end{array}$ & $\begin{array}{c}\text { Number of } \\
\text { products }\end{array}$ \\
\hline Injectable & Florifenicol & 7.5 & 7.5 & 7.5 & 1.00 & 1 \\
\hline Injectable & Gentamicin (YA) & 1.3 & 1.3 & 1.3 & 1.00 & 1 \\
\hline Injectable & Lincomycin & 10.0 & 10.0 & 10.0 & 1.00 & 2 \\
\hline Injectable & Oxytetracycline & 5.0 & 6.7 & 5.9 & 1.00 & 13 \\
\hline Injectable & Oxytetracycline (YA) & 12.5 & 16.7 & 14.6 & 1.00 & 3 \\
\hline Injectable & Procaine benzylpenicillin & 12.0 & 15.0 & 13.5 & 1.00 & 7 \\
\hline Injectable & Procaine benzylpenicillin (LA) & 6.7 & 6.7 & 6.7 & 1.00 & 2 \\
\hline Injectable & Procaine benzylpenicillin_combi (LA) & 1.5 & 1.5 & 1.5 & 1.00 & 1 \\
\hline Injectable & Sulfadoxine_trimethoprim & 13.3 & 13.3 & 13.3 & 1.00 & 5 \\
\hline Injectable & Sulfadoxine_trimethoprim (YA) & 25.0 & 25.0 & 25.0 & 1.00 & 5 \\
\hline Injectable & Tiamulin & 11.0 & 11.0 & 11.0 & 1.00 & 1 \\
\hline Injectable & Trimethoprim_sulfadoxine & 2.4 & 2.4 & 2.4 & 1.00 & 5 \\
\hline Injectable & Trimethoprim_sulfadoxine (YA) & 5.0 & 5.0 & 5.0 & 1.00 & 6 \\
\hline Injectable & Tulathromycin (LA) & 0.3 & 0.3 & 0.3 & 1.00 & 2 \\
\hline Injectable & Tylosin & 5.5 & 5.5 & 5.5 & 1.00 & 1 \\
\hline Bolus & Neomycin (supp) (YA) & 5 & 12.5 & 10 & 0.92 & 2 \\
\hline Bolus & Neomycin (YA) & 8.9 & 33.3 & 17.8 & 1.11 & 6 \\
\hline Bolus & Oxytetracycline (YA) & 5 & 55 & 18.9 & 1.39 & 9 \\
\hline Bolus & Spectinomycin (YA) & 12.5 & 25.0 & 18.8 & 1.00 & 2 \\
\hline Bolus & Succinylsulfathiazole (supp) (YA) & 24.0 & 48.0 & 36.0 & 1.00 & 1 \\
\hline Bolus & Sulfaguanidine (YA) & 83.8 & 83.8 & 83.8 & 1.00 & 2 \\
\hline Bolus & Sulfamethazine (YA) & 48.8 & 187.5 & 118.1 & 1.00 & 2 \\
\hline Bolus & Sulfanilamide (YA) & 73.1 & 73.1 & 73.1 & 1.00 & 1 \\
\hline Bolus & Sulfathiazole (YA) & 41.8 & 73.1 & 57.4 & 1.00 & 3 \\
\hline Bolus & Tetracycline (YA) & 12.8 & 17.8 & 15.3 & 1.00 & 2 \\
\hline Bolus & Toltrazuril (YA) & 20.0 & 20.0 & 20.0 & 1.00 & 1 \\
\hline
\end{tabular}

a Bolus, administered as individual oral treatment.

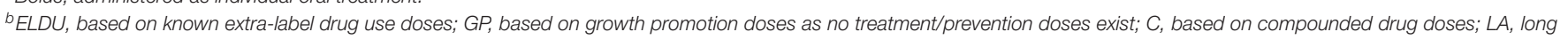
acting; YA, based on doses indicated for young animals; supp, based on doses from multiple ingredient products with low doses of antimicrobials.

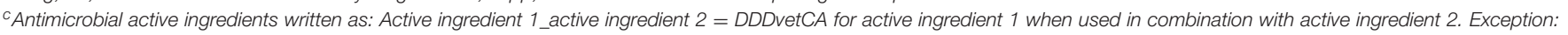
Benzathine Benzylpenicillin combi = Benzathine Benzylpenicillin in combination with any other antimicrobial active ingredient.

${ }^{d}$ Ratio mean dose:median dose $=$ DDDvetCA/median dose.

DDDvetCAs were assigned from ELDU doses for bambermycin and procaine benzylpenicillin administered through feed, as the in-feed products containing these AAIs do not include doses for pigs in their product information, however, surveillance indicates use by this route of administration. Unlike poultry, some DDDvetCAs were assigned using compounded product doses (Table 7).

\section{Comparison Between DDDvetCAs and EMA's DDDvets}

In pigs, comparisons between DDDvetCAs and DDDvets was possible for all routes of administration. Fifty-one DDDvetCAs could be compared to DDDvets (Table 8). The remaining 24 DDDvetCAs did not have any corresponding DDDvet.

As with poultry, results of the comparison showed some similarities and differences between the two sets of DDD for animals. Table 5 shows the frequency and proportion of DDDvetCA that were larger, smaller, or equivalent to their corresponding DDDvet using the DDDvetCA/DDDvet ratio. More specifically, DDDvetCAs and DDDvets were similar $( \pm 10 \%)$ for water administered amoxicillin, lincomycinspectinomycin, apramycin, and sulfamethazine, and for injectable ceftiofur, lincomycin, procaine benzylpenicillin, sulfadoxine_trimethoprim, and tiamulin. All feed DDDvetCAs were smaller than their corresponding DDDvet (Table 5). Overall for pigs, a difference of more than 50\% was observed between $35 \%$ of the DDDvetCAs and their corresponding DDDvets (e.g., enrofloxacin injectable DDDvetCA $=7.5$ $\mathrm{mg} / \mathrm{kg} /$ day; DDDvet $=3.4 \mathrm{mg} / \mathrm{kg} /$ day $)$.

\section{Other Observations in Pigs}

An examination of the Health Canada categorization for all DDDvetCAs in pigs revealed that two Health Canada Category I AAIs, namely ceftiofur and enrofloxacin, were licensed for use in pigs (19). Sixteen AAIs were Category II, with the remainder in Categories III and IV, or uncategorized (as for poultry). 
TABLE 7 | The Canadian defined daily doses for animals (DDDvetCA) in $\mathrm{mg} / \mathrm{kg}_{\text {pig }} /$ day for antimicrobials used in pig production, by antimicrobial active ingredient and route of administration.

\begin{tabular}{|c|c|}
\hline Antimicrobial active ingredient ${ }^{a, b}$ & DDDvetCA (mg/kg/day) \\
\hline \multicolumn{2}{|l|}{ FEED } \\
\hline Avilamycin & 3.2 \\
\hline Bacitracin & 4.5 \\
\hline Bambermycin (ELDU) (GP) & 0.1 \\
\hline Chlortetracycline & 10.4 \\
\hline Lincomycin & 5.0 \\
\hline Lincomycin_spectinomycin & 0.9 \\
\hline Narasin (GP) & 0.6 \\
\hline Oxytetracycline & 7.6 \\
\hline Penicillin G & 1.3 \\
\hline Procaine Penicillin G (ELDU) & 13.2 \\
\hline Salinomycin (GP) & 1.0 \\
\hline Spectinomycin_lincomycin & 0.9 \\
\hline Sulfamethazine & 4.4 \\
\hline Tiamulin & 5.7 \\
\hline Tilmicosin & 12.0 \\
\hline Tylosin & 3.1 \\
\hline Tylvalosin & 1.7 \\
\hline Virginiamycin & 3.3 \\
\hline \multicolumn{2}{|l|}{ INJECTABLE } \\
\hline Ampicillin & 6.0 \\
\hline Benzathine penicillin G-combic $(\llcorner A)$ & 1.2 \\
\hline Ceftiofur & 3.0 \\
\hline Ceftiofur (LA) & 1.0 \\
\hline Enrofloxacin & 7.5 \\
\hline Florifenicol & 7.5 \\
\hline Gentamicin (YA) & 1.3 \\
\hline Lincomycin & 10.0 \\
\hline Oxytetracycline & 5.9 \\
\hline Oxytetracycline (YA) & 14.6 \\
\hline Procaine Penicillin G & 13.5 \\
\hline Procaine Penicillin G (LA) & 6.7 \\
\hline Procaine Penicillin G_combic $(L A)$ & 1.5 \\
\hline Sulfadoxine_trimethoprim & 13.3 \\
\hline Sulfadoxine_trimethoprim (YA) & 25.0 \\
\hline Tiamulin & 11.0 \\
\hline Trimethoprim_sulfadoxine & 2.4 \\
\hline Trimethoprim_sulfadoxine (YA) & 5.0 \\
\hline Tulathromycin (LA) & 0.3 \\
\hline Tylosin & 5.5 \\
\hline \multicolumn{2}{|l|}{ WATER } \\
\hline Amoxicillin & 16.0 \\
\hline Ampicillin (C) & 20.0 \\
\hline Apramycin & 10.0 \\
\hline Gentamicin (C) & 1.1 \\
\hline Lincomycin & 3.3 \\
\hline Lincomycin_spectinomycin & 2.2 \\
\hline Neomycin & 12.5 \\
\hline Oxytetracycline & 14.6 \\
\hline
\end{tabular}

(Continued)
TABLE 7 | Continued

Antimicrobial active ingredient ${ }^{a, b}$

DDDvetCA (mg/kg/day)

\begin{tabular}{|c|c|}
\hline Penicillin G & 17.8 \\
\hline Penicillin G (supp) (GP) & 3.6 \\
\hline Penicillin V (C) & 28.2 \\
\hline Spectinomycin_lincomycin & 4.5 \\
\hline Streptomycin (supp) (GP) & 18.5 \\
\hline Sulfadiazine_trimethoprim (C) & 32.4 \\
\hline Sulfamerazine (supp) & 3.3 \\
\hline Sulfamethazine & 79.0 \\
\hline Sulfamethazine (supp) & 6.3 \\
\hline Sulfapyridine & 33.3 \\
\hline Sulfathiazole & 46.2 \\
\hline Sulfathiazole (supp) & 10.3 \\
\hline Tetracycline & 8.6 \\
\hline Tiamulin & 4.9 \\
\hline Tilmicosin (C) & 10.0 \\
\hline Trimethoprim_sulfadiazine (C) & 7.1 \\
\hline Tylosin & 16.7 \\
\hline Tylvalosin & 5.0 \\
\hline \multicolumn{2}{|l|}{ BOLUS $^{d}$} \\
\hline Neomycin (supp) (YA) & 9.2 \\
\hline Neomycin (YA) & 19.7 \\
\hline Oxytetracycline (YA) & 26.2 \\
\hline Spectinomycin (YA) & 18.8 \\
\hline Succinylsulfathiazole (supp) (YA) & 36.0 \\
\hline Sulfaguanidine (YA) & 83.8 \\
\hline Sulfamethazine (YA) & 118.1 \\
\hline Sulfanilamide (YA) & 73.1 \\
\hline Sulfathiazole (YA) & 57.4 \\
\hline Tetracycline (YA) & 15.3 \\
\hline Toltrazuril (YA) & 20.0 \\
\hline
\end{tabular}

a DDDvetCA, Canadian defined daily dose for animals; $L A$, long-acting; YA, young animal; supp, supplements; ELDU, extra-label drug use; GP, growth promotion; C, compounded drug use.

${ }^{b}$ Antimicrobial active ingredients written as: Active ingredient 1_active ingredient 2 = DDDvetCA for active ingredient 1 when used in combination with active ingredient 2.

${ }^{c}$ Benzathine Penicillin G-combi and Procaine Penicillin G-combi $(L A)$ : when combined with any other antimicrobial active ingredient.

${ }^{d}$ Administered as individual oral treatments.

\section{Overall Results}

Across both species, more DDDvetCAs were assigned for AAIs used in pigs than for poultry (Table 3). There were 53 feed, water and bolus DDDvetCAs that could be matched by AAI to 40 oral DDDvets, and 17 injectable DDDvetCAs that could be matched by AAI to 14 parenteral DDDvets (Tables 5, 8).

\section{DISCUSSION}

\section{Assigning DDDvetCAs}

Assigning DDDvetCAs was a resource intensive and iterative process, and regular group discussions were needed to make a range of operational decisions. Examples of these decisions include, among others, the setup of the spreadsheet used to 
collect product information, how to interpret and handle various product information situations (such as combination products or dose ranges), and which doses to use for the determination of the mean dose (e.g., all doses or only unique doses). These decisions were sometimes revisited with the acquisition of new information.

Part of what made the DDDvetCA assignment resource intensive was the need for human resources to extract dose information from product information in the CVP and CMIB. At times, tracking down manufacturer and/or expert opinion was necessary where no licensed product dose information was available. Between 10 and $15 \mathrm{~min}$ were required to extract the required information from each product, provided the product information was comprehensive and clear. However, differences in the way product information and drug doses were written caused significant variation in the time needed to extract the information required. Some product information was clear and easy to understand, while others were more complex. Some products had doses for multiple indications, multiple species, or multiple routes of administration. For example, some water products included doses for individual animal dosing and for herd/flock dosing. The process became faster as familiarity with product information increased.

The decision to exclude growth promotion doses from the assignment of DDDvetCAs was consistent with EMA's guidelines, as in the European Union, the use of antimicrobial products for growth promotion is not permitted, and as a result, EMA's DDDvets are based on treatment and prevention doses only (9). In Canada, as of December 1, 2018, all antimicrobial products considered medically important by Health Canada will no longer be labeled for growth promotion purposes (20). By excluding growth promotion doses, the DDDvetCAs will remain relevant after this change. The decision to assign separate DDDvetCAs to growth promotion AAIs was based on the need to quantify their use, as these AAIs appear in Canadian surveillance data.

A departure from EMA's guidelines was the assignment of DDDvetCAs to AAIs used in an extra-label manner in the species of interest. Prescribing antimicrobials in an extra-label manner is legal for veterinarians in Canada, when no approved product for the species of interest exists (21). For the same reason that DDDvetCAs were needed for growth promotion AAIs, DDDvetCAs were needed for ELDU AAIs where surveillance data indicated their use in Canada. Since these extra-label DDDvetCAs are based on used doses, rather than labeled doses, they more closely resemble used daily doses (22). We recognize that assigning DDDvetCAs to these extra-label AAIs was a departure from defined daily dose methodology, however, due to the need to quantify the use of these AAIs we decided to include them in the DDDvetCA assignment.

We followed EMA's DDDvet guidelines for assigning separate DDDvetCAs to AAIs used in combination formulations, when their mean daily doses differed from single ingredient formulations (9). In contrast, the World Health Organization's methodology for the assignment of human DDDs assigns a single DDD to AAIs used in combination, using the mean daily dose of the main AAI ingredient only (23). When combination AAI products are used, the World Health Organization's method will only account for the use of the main ingredient, while CIPARS' (and EMA's) method will account for the use of each of the AAI in the combination product. This will ensure that all AAI use is considered for future modeling with AMR data.

The decision to use an average, or mean, daily dose to assign DDDvetCAs was also consistent with EMA's guidelines and with the DDD in human medicine $(9,10)$. While examining the distribution of AAI doses, we investigated using the median daily dose to assign DDDvetCAs. Over $80 \%$ of mean and median daily doses were identical in each species, so whether the mean or median dose was used made little difference to the resulting DDDvetCAs. Where differences existed, the mean was almost always larger than the median, which suggested that for these cases there may be some high dose outliers influencing the mean. Using the mean daily dose kept the DDDvetCAs more closely aligned with the EMA's methodology and the definition of a DDDvet (9). Examining AMU farm surveillance data to see if these outlying doses are in use may prove interesting.

\section{Differences Between DDDvetCAs and EMA's DDDvets}

A major difference between DDDvetCAs and DDDvets is the stratification by routes of administration for products administered orally. EMA grouped the oral routes of administration together when assigning DDDvets, creating one category called oral $(9,12)$, while at CIPARS, we assigned DDDvetCAs to each oral route of administration separately. This difference in stratification very likely contributed to the differences between the feed, water and bolus DDDvetCAs and the oral DDDvets. Assigning DDDvetCAs separately to each oral route of administration will enable CIPARS to monitor changes in use between these routes of administration. An argument could be made that the DDDvetCAs should not be compared to DDDvets, due to the differences in route of administration stratification. However, we felt that these comparisons would be made by others, and by including the comparison in this study we could emphasize the strengths and limitations of doing so. The differences found between our feed, water and bolus DDDvetCAs and the oral DDDvets may have been less evident if we combined the oral routes of administration together in a similar manner to EMA. Even with the differences in stratification, some of the feed, water and bolus DDDvetCAs were identical or very close to the corresponding oral DDDvets.

CIPARS' method of assigning DDDvetCAs by using only unique AAI doses to calculate the mean daily dose also differed from EMA's guidelines (9). EMA's method of using the minimum and maximum daily doses to determine the mean daily dose meant that the doses on either end of the dose range had a greater effect on the mean. In contrast, by using the range of unique doses, any doses in the middle of the range have a moderating effect on the mean dose. For example, the unique daily doses for chlortetracycline in feed are 55, 110, 220, and $656 \mathrm{mg}$ per $\mathrm{kg}$ of feed. If we used EMA's method, the mean daily dose would be 
TABLE 8 | The ratio of the Canadian defined daily doses for animals (DDDvetCA) by route of administration to the European Medicine Agency's defined daily dose for animals (DDDvet) in pigs.

\begin{tabular}{|c|c|c|c|c|c|}
\hline Antimicrobial active ingredient ${ }^{a}$ & DDDvetCA & Canadian ROA & DDDvet $^{\mathbf{b}}$ & EMA ROA ${ }^{c}$ & Ratio $^{d}$ \\
\hline Amoxicillin & 16.0 & Water & 17.0 & Oral & 0.9 \\
\hline Ampicillin & $20.0^{\mathrm{e}}$ & Water & 30.0 & Oral & 0.7 \\
\hline Ampicillin & 6.0 & Injectable & 12.0 & Parenteral & 0.5 \\
\hline Apramycin & 10.0 & Water & 9.0 & Oral & 1.1 \\
\hline Benzathine Penicillin G_combi (LA) & 1.2 & Injectable & 5.4 & Parenteral & 0.2 \\
\hline Ceftiofur (LA) & 1.0 & Injectable & 0.8 & Parenteral & 1.3 \\
\hline Ceftiofur & 3.0 & Injectable & 3.0 & Parenteral & 1.0 \\
\hline Chlortetracycline & 10.4 & Feed & 31.0 & Oral & 0.3 \\
\hline Enrofloxacin & 7.5 & Injectable & 3.4 & Parenteral & 2.2 \\
\hline Florifenicol & 7.5 & Injectable & 9.5 & Parenteral & 0.8 \\
\hline Gentamicin & $1.1^{\mathrm{e}}$ & Water & 1.4 & Oral & 0.8 \\
\hline Gentamicin & $1.3^{f}$ & Injectable & 1.4 & Parenteral & 0.9 \\
\hline Lincomycin & 5.0 & Feed & 7.6 & Oral & 0.7 \\
\hline Lincomycin & 10.0 & Injectable & 10.0 & Parenteral & 1.0 \\
\hline Lincomycin & 3.3 & Water & 7.6 & Oral & 0.4 \\
\hline Lincomycin_spectinomycin & 0.9 & Feed & 2.2 & Oral & 0.4 \\
\hline Lincomycin_spectinomycin & 2.2 & Water & 2.2 & Oral & 1.0 \\
\hline Neomycin & $19.7^{f}$ & Bolus & 25.0 & Oral & 0.8 \\
\hline Neomycin & 12.5 & Water & 25.0 & Oral & 0.5 \\
\hline Oxytetracycline & $26.2^{f}$ & Bolus & 26.0 & Oral & 1.0 \\
\hline Oxytetracycline & $14.6^{f}$ & Injectable & 7.5 & Parenteral & 1.9 \\
\hline Oxytetracycline & 7.6 & Feed & 26.0 & Oral & 0.3 \\
\hline Oxytetracycline & 5.9 & Injectable & 7.5 & Parenteral & 0.8 \\
\hline Oxytetracycline & 14.6 & Water & 26.0 & Oral & 0.6 \\
\hline Penicillin G & 1.3 & Feed & 48.0 & Oral & $<0.1$ \\
\hline Penicillin G & 17.8 & Water & 48.0 & Oral & 0.4 \\
\hline Procaine Penicillin G & 13.5 & Injectable & 13.0 & Parenteral & 1.0 \\
\hline Spectinomycin & $18.8^{f}$ & Bolus & 33.0 & Oral & 0.6 \\
\hline Spectinomycin_lincomycin & 0.9 & Feed & 3.4 & Oral & 0.3 \\
\hline Spectinomycin_lincomycin & 4.5 & Water & 3.4 & Oral & 1.3 \\
\hline Sulfadiazine_trimethorprim & $32.4^{\mathrm{e}}$ & Water & 23.0 & Oral & 1.4 \\
\hline Sulfadoxine_trimethoprim & $13.6^{f}$ & Injectable & 14.0 & Oral & 1.0 \\
\hline Sulfaguanidine & $83.8^{f}$ & Bolus & 54.0 & Oral & 1.6 \\
\hline Sulfamethazine & $118.1^{\dagger}$ & Bolus & 92.0 & Oral & 1.3 \\
\hline Sulfamethazine & 4.4 & Feed & 92.0 & Oral & $<0.1$ \\
\hline Sulfamethazine & 79.0 & Water & 92.0 & Oral & 0.9 \\
\hline Tetracycline & $15.3^{f}$ & Bolus & 49.0 & Oral & 0.3 \\
\hline Tetracycline & 8.6 & Water & 49.0 & Oral & 0.2 \\
\hline Tiamulin & 5.7 & Feed & 9.7 & Oral & 0.6 \\
\hline Tiamulin & 11.0 & Injectable & 12.0 & Parenteral & 0.9 \\
\hline Tiamulin & 4.9 & Water & 9.7 & Oral & 0.5 \\
\hline Tilmicosin & $10.0^{\mathrm{e}}$ & Water & 15.0 & Oral & 0.7 \\
\hline Tilmicosin & 12.0 & Feed & 15.0 & Oral & 0.8 \\
\hline Trimethoprim_sulfadiazine & 7.1 & Water & 4.7 & Oral & 1.5 \\
\hline Trimethoprim_sulfadoxine & $5.0^{f}$ & Injectable & 4.7 & Parenteral & 1.1 \\
\hline Trimethoprim_sulfadoxine & 2.4 & Injectable & 3.0 & Parenteral & 0.8 \\
\hline Tylosin & 3.1 & Feed & 12.0 & Oral & 0.3 \\
\hline Tylosin & 5.5 & Injectable & 13.0 & Parenteral & 0.4 \\
\hline Tylosin & 16.7 & Water & 12.0 & Oral & 1.4 \\
\hline
\end{tabular}


TABLE 8 | Continued

\begin{tabular}{lccccc}
\hline Antimicrobial active ingredient $^{\mathbf{a}}$ & DDDvetCA & Canadian ROA & DDDvet $^{\text {b }}$ & EMA ROA $^{\mathbf{c}}$ & Ratio $^{\mathbf{d}}$ \\
\hline Tylvalosin & 1.7 & Feed & 3.6 & Oral & 0.5 \\
Tylvalosin & 5.0 & Water & 3.6 & Oral & 1.4 \\
\hline
\end{tabular}

Ratios above 1.5 and below 0.5 , indicating substantial differences in these standardized doses, are in bold print.

${ }^{a}$ Antimicrobial active ingredients written as: Active ingredient 1_active ingredient 2 =DDDvetCA for active ingredient 1 when used in combination with active ingredient 2.

${ }^{b}$ European Medicines Agency. Defined daily doses for animals (DDDvet) and defined course doses for animals (DCDvet). 2016.

${ }^{c}$ The EMA combined in-feed, in-water and oral bolus routes of administration into one oral DDDvet.

${ }^{d}$ Ratio $=$ DDDvetCA/DDDvet.

${ }^{e} D D D v e t C A$ assigned using compounded doses.

${ }^{f} D D D$ vetCA assigned using young animal doses.

$355.5 \mathrm{mg}$ per $\mathrm{kg}$ of feed and a DDDvet of $14.2 \mathrm{mg} / \mathrm{kg} / \mathrm{day}$, while using our method results in a mean daily dose of $260.3 \mathrm{mg} / \mathrm{kg}$ feed and a DDDvetCA of $10.4 \mathrm{mg} / \mathrm{kg} /$ day.

An example of yet another way of calculating the mean daily dose is Postma et al.'s (13) method of averaging every dose found, regardless of how often each dose appears in product information. Postma et al. (13) felt this method was the clearest but acknowledged that the number of products that contained a specific AAI influenced the mean. Since the number of products containing an AAI does not necessarily reflect the frequency of use, we opted for a more neutral approach and attributed equal weight to every unique dose reported in the CVP and CMIB $(16,17)$.

Another difference between CIPARS', EMA's, and Postma et al.'s (13) methodology is in the approach to young animal doses. EMA included both young and adult doses in the calculation of a single average daily dose that could then be applied to all ages of animals (9). Postma et al. (13) followed human medicine methodology by incorporating only adult doses in the assignment of their DDDvets. CIPARS chose to separate young animal doses from the rest and assign age stratified DDDvetCAs in those AAIs with young animal doses. This decision was made because age-stratified AMU data were available to CIPARS, or would be available in the future, making age-stratified DDDvetCAs useful.

Defined daily dose methodology in human medicine deals with differences in dosing by age by incorporating the weight of a standard adult $(70 \mathrm{~kg}$ ) into the assignment of the DDD (10). As a result, human DDD are assigned in $\mathrm{mg} /$ day, rather than $\mathrm{mg} / \mathrm{kg} /$ day as in veterinary medicine (10). Consequently, the World Health Organization's guidelines for ATC classification and DDD assignment in humans states that DDDs in children ages $>1$ month to 18 years are impossible to assign, as pediatric doses are dependent on age and weight, which vary widely (10). An advantage of assigning DDD for animals in $\mathrm{mg} / \mathrm{kg} /$ day rather than $\mathrm{mg} /$ day is that they can be applied to animals in various weight and/or age categories. Assigning specific young animal DDDvetCAs, where young animal doses exist, can help us avoid the challenges experienced in human medicine when measuring AMU in pediatrics (24).

There are many other reasons for the observed differences in DDD for animals between CIPARS and EMA, one of which is that EMA may have had a wider range of AAI doses to work with, due to the collection of AAI doses from nine European countries (9). However, fully elucidating all the reasons for the differences between the EMA's DDDvets and the DDDvetCAs was outside the scope of this project. We can speculate that different labeling regulations, different treatment indications, and different husbandry practices may all contribute. Ultimately, whether the DDDvet or the DDDvetCA for an AAI is higher or lower does not necessarily reflect the use of that AAI in practice. DDD for animals are intended to be a technical measurement only (9). They are useful when standardized doses are needed for monitoring of trends in AMU and other purposes, in a variety of populations, whether they be national or regional.

\section{The Need for DDDvetCAs}

The findings from this project confirmed the need for national DDDvetCAs for Canada for a few reasons. One reason was the observation that the DDDvets did not cover all the AAIs used in veterinary medicine in Canada. Also, while drawing conclusions from differences between DDDvetCAs and DDDvets assigned to oral routes of administration is difficult due to issues previously discussed, the differences observed between injectable DDDvetCAs and parenteral DDDvets appear to confirm the need for DDDvetCA that reflect antimicrobial selection pressure in a Canadian context.

The assigned DDDvetCAs have already been used by CIPARS for reporting farm-level surveillance data $(5,25)$. In the annual CIPARS report, the DDDvetCAs were used in the calculation of dose-based AMU indicators such as the number of defined daily doses for animals per 1,000 animal-days (26), and the number of defined daily doses for animals per population correction unit (5). Indicators such as these that use the DDDvetCAs will be valuable for in-country application to Canadian AMU data.

However, when comparing AMU between countries, using country specific DDD for animals such as the DDDvetCAs, may not be appropriate, due to the same challenges we observed when comparing DDDvetCAs and DDDvets. Differences in methodology and in antimicrobials authorized for use, among other issues, means that when reporting AMU internationally, it would be preferable for all reporting countries to use a set of international DDD for animals assigned using a single methodology. Ideally, these international DDD for animals would be assigned from globally represented product doses. Hence, the objectives of the reporting, whether national or international, will determine the choice of whether to use country-specific or international DDD for animals. 


\section{Limitations}

A limitation of the DDDvet methodology is that they are based on AAI doses from product information, which may not reflect the use of the AAI in practice $(9,10)$. When measuring AMU from surveillance data, where dosing practices may vary widely, the assigned DDDvets provide a consistent and transparent technical method for adjusting weight-based measures of AMU by dose. Where more specific information on AMU exposure is required, using used daily doses (UDD) may be more appropriate, noting that the results obtained from such an analysis will specific to the population from which the UDD were determined (22). Using UDD would require detailed data, including used doses and animal weights at treatment, and the results would be specific to a population at a point in time, as used doses and dosing practices frequently change.

The DDDvetCAs will need to be reviewed periodically as product doses may change, new products may be registered, or older ones discontinued. Also, new indications for use may be added to product information and changes in approved species may occur. While a DDDvetCA may be subject to review in specific instances, the aim is for the assigned DDDvetCAs to remain stable over time. This stability over time will allow for AMU trends to be followed long-term without frequent changes that will complicate analyses and interpretation. Future revisions will be aided by the Microsoft Excel ${ }^{\circledR} 2010$ spreadsheet designed and used for tabulation and calculation of the DDDvetCAs, which will function as a database. To make future revisions easier, the development of an automated product registration system to flag product dose changes or new products would be helpful.

\section{CONCLUSION}

The study of AMU is essential, enabling the examination of the impact on animal and human health due to the extent, nature, and determinants of AMU, and due to the associations between AMU and AMR. The DDDvetCAs will be valuable in the study of

\section{REFERENCES}

1. Rushton J, Pinto Ferreira J, Stärk KDC. Antimicrobial resistance: the use of antimicrobials in the livestock sector. In: OECD Food, Agriculture and Fisheries Papers, Paris: OECD Publishing (2014). doi: $10.1787 / 5$ jxvl3dwk3f0-en

2. O'Neill J. The Review on Antimicrobial Resistance. Tackling Drug-resistant Infections Globally: Final Report and Recommendations (2016).

3. MARAN Nethmap. NethMap 2017: Consumption of Antimicrobial Agents and Antimicrobial Resistance among Medically Important Bacteria in the Netherlands/MARAN 2017: Monitoring of Antimicrobial Resistance and Antibiotic Usage in Animals in the Netherlands in 2016 (2017).

4. DANMAP. DANMAP 2016-Use of Antimicrobial Agents and Occurrence of Antimicrobial Resistance in Bacteria from Food Animals, Food and Humans in Denmark (2017).

5. Government of Canada. Canadian Integrated Program for Antimicrobial Resistance Surveillance (CIPARS) 2016 Annual Report (2018).

6. European Surveillance of Veterinary Antimicrobial Consumption. ESVAC: Vision, Strategy and Objectives 2016-2020. London: European Medicines Agency (2017)
AMU in Canada, and while the process of assigning DDDvetCAs for the first time was challenging and resource intensive, maintaining them will require fewer resources. EMA's published principles for assigning DDDvets were an invaluable source of guidance and information for the creation of DDDvetCAs (9). Future steps for CIPARS include exploring DDDvetCA assignment for other production types such as cattle (beef and dairy), veal, and farmed fish.

\section{DATA AVAILABILITY}

The datasets generated for this study are available on request to the corresponding author.

\section{AUTHOR CONTRIBUTIONS}

All authors listed have made a substantial, direct and intellectual contribution to the work, and approved it for publication.

\section{FUNDING}

No specific funding was received for this project, which was part of the routine work of the Canadian Integrated Program for Antimicrobial Resistance Surveillance (CIPARS) of the Public Health Agency of Canada.

\section{ACKNOWLEDGMENTS}

The authors thank Melissa Cummings, Maggie McCann, Courtney Primeau, Ashley Vanderlaan, Lindsay Messerschmidt and Jeanette Cooper for their assistance with this project. We thank Dr. Cécile Ferrouillet (Université de Montréal) and Dr. Anne Deckert (Public Health Agency of Canada) for their contributions to the assignment of DDDvetCAs in pigs, and the AMU metrics working group for their suggestions and input.
7. Government of Canada. Antimicrobial Resistance and Use in Canada: A Federal Framework for Action. Ottawa, ON: Public Health Agency of Canada (2014).

8. World Health Organization. Global Action Plan on Antimicrobial Resistance. Geneva: World Health Organization (2015).

9. European Medicines Agency. Principles on Assignment of Defined Daily Dose for Animals (DDDvet) and Defined Course Dose for Animals (DCDvet) (2015).

10. WHO Collaborating Centre for Drug Statistics Methodology. Guidelines for ATC Classification and DDD Assignment, 2019 (2018).

11. AliAbadi FS, Lees P. Antibiotic treatment for animals: effect on bacterial population and dosage regimen optimisation. Int J Antimicrob Agents. (2000) 14:307-13. doi: 10.1016/S0924-8579(00)00142-4

12. European Medicines Agency. Defined Daily Doses for Animals (DDDvet) and Defined Course Doses for Animals (DCDvet) (2016).

13. Postma M, Sjölund M, Collineau L, Lösken S, Stärk KDC, Dewulf J, et al. Assigning defined daily doses animal: A European multicountry experience for antimicrobial products authorized for usage in pigs. J Antimicrob Chemother. (2015) 70:294-302. doi: 10.1093/jac/ dku347

14. MARAN 2018. Monitoring of Antimicrobial Resistance and Antibiotic Usage in Animals in the Netherlands in 2017 (2018). 
15. DANMAP 2017. Use of Antimicrobial Agents and Occurrence of Antimicrobial Resistance in Bacteria from Food Animals, Food and Humans in Denmark (2018).

16. Canadian Animal Health Institute. Compendium of Veterinary Products, Canadian ed. Hensall, ON: A.J. Bayley (2016).

17. Canadian Food Inspection Agency. Compendium of Medicating Ingredient Brochures. (2018). Available online at: http://www.inspection.gc.ca/animals/ feeds/medicating-ingredients/eng/1300212600464/1320602461227 (accessed April 4, 2018).

18. European Medicines Agency. Sales of Veterinary Antimicrobial Agents in 30 European Countries in 2016-Trends from 2010 to 2016, Eighth ESVAC Report. (2018)

19. Health Canada. Categorization of Antimicrobial Drugs Based on Importance in Human Medicine. (2009). Available online at: https://www.canada. ca/en/health-canada/services/drugs-health-products/veterinary-drugs/ antimicrobial-resistance/categorization-antimicrobial-drugs-basedimportance-human-medicine.html (accessed July 13, 2016).

20. Health Canada's Veterinary Drugs Directorate. Notice to Stakeholders: Collaborative Efforts to Promote the Judicious Use of Medically-important Antimicrobial Drugs in Food Animal Production. (2014). Available online at: https://www.canada.ca/en/health-canada/services/drugs-healthproducts/veterinary-drugs/antimicrobial-resistance/notice-stakeholderscollaborative-efforts-promote-judicious- use-medically-importantantimicrobial-drugs-food-animal-production.html (accessed August 11, 2017).

21. Health Canada's Veterinary Drugs Directorate. Policy on Extra-Label Drug Use (ELDU) in Food Producing Animals. (2008). Available online at: https://www.canada.ca/en/health-canada/services/drugs-health-products/ veterinary-drugs/extra-label-drug-use/policy-extra-label-drug-use-eldufood-producing-animals.html (accessed January 30, 2019).
22. Timmerman T, Dewulf J, Catry B, Feyen B, Opsomer G, de Kruif A, et al. Quantification and evaluation of antimicrobial drug use in group treatments for fattening pigs in Belgium. Prev Vet Med. (2006) 74:251-63. doi: 10.1016/j.prevetmed.2005. 10.003

23. World Health Organization. Definition and General Considerations of DDD. (2016). Available online at: https://www.whocc.no/ddd/definition_ and_general_considera/ (accessed February 12, 2017).

24. Gravatt LA, Pakyz AL. Challenges in measuring antibiotic consumption. Curr Infect Dis Rep. (2013) 15:559-63. doi: 10.1007/s11908-0130374-9

25. Agunos A, Léger DF, Carson CA, Gow SP, Bosman A, Irwin RJ, et al. Antimicrobial use surveillance in broiler chicken flocks in Canada, 2013-2015. PLOS ONE. (2017) 12:e0179384. doi: 10.1371/journal.pone .0179384

26. Government of Canada. Canadian Integrated Program for Antimicrobial Resistance Surveillance (CIPARS) 2015 Annual Report. (2016).

Conflict of Interest Statement: The authors declare that the research was conducted in the absence of any commercial or financial relationships that could be construed as a potential conflict of interest.

Copyright (C) 2019 Bosman, Loest, Carson, Agunos, Collineau and Léger. This is an open-access article distributed under the terms of the Creative Commons Attribution License (CC BY). The use, distribution or reproduction in other forums is permitted, provided the original author(s) and the copyright owner(s) are credited and that the original publication in this journal is cited, in accordance with accepted academic practice. No use, distribution or reproduction is permitted which does not comply with these terms. 